\title{
The Effect of Air Knife Wiping Speed on Galvanized Coating Weight and Thickness
}

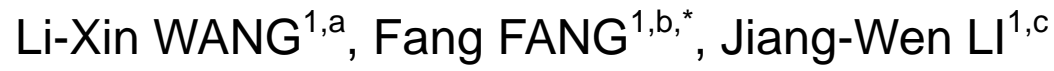 \\ ${ }^{1}$ Research and Development Center, Wuhan Iron and Steel Co., Wuhan, China

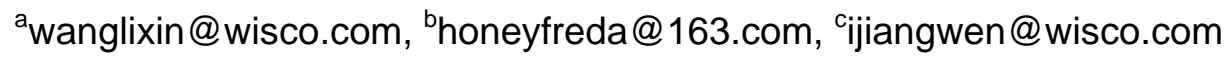 \\ ${ }^{*}$ Corresponding author
}

Keywords: Hot Dipping Process, Coating Weight, Coating Thickness, Air Knife Flow Rate.

\begin{abstract}
An important factor of wiping parameters-wiping speed was controlled precisely in the paper to study its effect on galvanized coating weight and thickness. The experiment was conducted by a hot dipping process simulator, the experimental steel was immersed in a zinc bath of $\mathrm{Zn}-0.24 \mathrm{Al}(\mathrm{vol} \%)$ at stable temperature of $460^{\circ} \mathrm{C}$ for $3.5 \mathrm{~s}$, with fixed atmosphere of $10 \mathrm{H}_{2} / 90 \mathrm{~N}_{2}$ (vol\%), dew point of $-60^{\circ} \mathrm{C}$. The wiping speed was conducted from 300 to $700 \mathrm{~mm} / \mathrm{s}$, the coating weight was decreased from 66.55 to $56.19 \mu \mathrm{m}$ then increased to $77.57 \mu \mathrm{m}$, the thickness was in the trend decreased from 9.17 to $7.84 \mu \mathrm{m}$ then increased to $13.18 \mu \mathrm{m}$. The minimum value was both when the wiping speed was at $500 \mathrm{~mm} / \mathrm{s}$.
\end{abstract}

\section{Introduction}

Automotive body-in-white weight reduction and safety standards improvement are main trends in automobile industry. Future Steel Vehicle project, which is organized by the International Iron and Steel Institute, shows that the vehicle weight can be reduced 35\% under the conditions of satisfying 5 star crash standards by means of the application high strength steel and advanced manufacturing technologies ${ }^{[1]}$. The service life of car is closely related to the corrosion resistance of steel plate. HDG automotive steel sheet is widely used in auto industry for its better corrosion resistance. The ratio of HDG automotive steel sheet reaches to $100 \%$ in some new cars ${ }^{[2]}$.

With the first modern continuous galvanizing line in China imported from Germany by Wuhan Iron and Steel Group Corporation (WISCO) in 1979, it is been almost half a century progress for WISCO to produce high-tech galvanizing and galvanealing products. In the same way, an expert experimental equipment- hot dipping process simulator (HDPS) which is popular in the world in recent years to research high strength steel and new coating was introduced and assembled in WISCO. The simulator can control parameters accurately which makes sure the laboratory results are close to industry production. Some basic jobs were done by using the simulator which is very useful for further research work. Among which, to make sure the experimental steel has a desirable coating weight and thickness, series of parameters were conducted, and in this study on of the important parameter-wiping speed was controlled precisely to study its effect on the galvanized coating surface quality.

\section{Experimental Procedure}

Been a kind of settled steel for basic research works, the experimental steel was normal deep drawing steel which was cast, hot rolled, pickled, cold rolled in industry production and cut by 110 $\mathrm{mm} \times 220 \mathrm{~mm}$ samples. An Iwatani Surtec Hot Dip Process Simulator (HDPS) was used to simulate the heat treatment and hot dip galvanizing of a classical Continuous Galvanizing Line (CGL) ${ }^{[3]}$. The samples were partially immersed in the Zinc bath for coating analysis to make the thermocouple will not be immersed to the zinc melt to avoid short circuit. Samples were cleaned and dried per standard practice ${ }^{[4]}$. Sample thermal profiles were controlled using a type-K thermocouple welded to the sample in combination with a standard process controller, to produce suitable surfaces for reactive wetting and high quality coating production. 
To study the effect of wiping speed on coating surface quality, all the other heat treatment and dipping cycles were as fixed. All process atmospheres comprised $10 \mathrm{H}_{2} / 90 \mathrm{~N}_{2}$ (vol\%) with a constant dew point of $-60^{\circ} \mathrm{C}$. All galvanizing baths were held at $460^{\circ} \mathrm{C}$, with no iron-saturated and contained $0.24 \mathrm{wt} \%$ dissolved Al. The immersion time for all samples was 3.5s. Triplicate samples were produced for all thermal cycles. Air knife flow rate was designed on $500 \mathrm{l} / \mathrm{min}$. Then different air knife wiping speed from $300 \sim 700 \mathrm{~mm} / \mathrm{s}$ were conducted. The hot dipping process parameters for experimental steel were presented in Table 1.

Tab.1 The Hot Dipping Process Parameters for Experimental Steel

\begin{tabular}{ccccccc}
\hline Code & $\begin{array}{c}\text { Soaking } \\
\text { temp, }{ }^{\circ} \mathrm{C}\end{array}$ & $\begin{array}{c}\text { Fast cooling } \\
\text { rate, }{ }^{\circ} \mathrm{C} / \mathrm{s}\end{array}$ & $\begin{array}{c}\text { Final } \\
\text { cooling } \\
\text { temp, }{ }^{\circ} \mathrm{C}\end{array}$ & $\begin{array}{c}\text { Dipping } \\
\text { time, } \mathrm{s}\end{array}$ & $\begin{array}{c}\text { Air knife } \\
\text { flow rate, } \\
1 / \mathrm{min}\end{array}$ & $\begin{array}{c}\text { Air knife } \\
\text { wipping speed, } \\
\mathrm{mm} / \mathrm{s}\end{array}$ \\
\hline 1 & 800 & 25 & 460 & 3.5 & 500 & 300 \\
2 & 800 & 25 & 460 & 3.5 & 500 & 400 \\
3 & 800 & 25 & 460 & 3.5 & 500 & 500 \\
4 & 800 & 25 & 460 & 3.5 & 500 & 600 \\
5 & 800 & 25 & 460 & 3.5 & 500 & 700 \\
\hline
\end{tabular}

Surface state (zinc coating weight and thickness) after hot dip galvanizing was analyzed by Glow Discharge Optical Emissivity Spectroscopy (GDOES). GD Profiler HR glow discharge optical emission spectrometer (Horiba Jobin Yvon, France) with a polychromater of 1 meter focal length (38 channels) and a monochromator of 1 meter focal length. Perthometer S2 surface roughness tester (Mahr Company, Germany), probe contact scan with the contact force of $0.7 \mathrm{mN}$, maximum scanning distance of $56.00 \mathrm{~mm}$ and vertical minimum calibration of $0.1 \mu \mathrm{m}$.

\section{Results and Discussions}

Tab.2 Coating Weight and Thickness with Different Wiping Speed

\begin{tabular}{cccc}
\hline Code & Weight, $\mathrm{g} / \mathrm{m}^{2}$ & Thickness, $\mu \mathrm{m}$ & WS, $\mathrm{mm} / \mathrm{s}$ \\
\hline 1 & 66.55 & 9.17 & 300 \\
2 & 60.45 & 8.21 & 400 \\
3 & 56.19 & 7.84 & 500 \\
4 & 61.16 & 8.42 & 600 \\
5 & 77.57 & 13.18 & 700 \\
\hline
\end{tabular}

The effect of air knife wiping speed on coating weight and thickness was shown in Table 2 and 
Fig.1. When WS was precisely controlled by the HDPS from 300 to $700 \mathrm{~mm} / \mathrm{s}$, which means the speed of sample moving password the air knife, the coating weight was all less than $80 \mathrm{~g} / \mathrm{m}^{2}$, and thickness was less than $14 \mu \mathrm{m}$. As WS increased from 600 to $700 \mathrm{~mm} / \mathrm{s}$, the coating weight and thickness both increased significantly that reached $77.57 \mathrm{~g} / \mathrm{m}^{2}$ and $13.18 \mu \mathrm{m}$, respectively. When the sample moved in a fast speed passing through the air knife, it will not have enough time to wipe and more zinc on the sample will be retained to the next step process - cooling up to room temperature. From Fig 1, it is obvious to see that, when WS was conducted from 300 to $500 \mathrm{~mm} / \mathrm{s}$, the coating weight decreased from 66.55 to $56.19 \mathrm{~g} / \mathrm{m}^{2}$, and with the increasing WS from 500 to $700 \mathrm{~mm} / \mathrm{s}$, the weight also increased from 56.19 to $77.57 \mathrm{~g} / \mathrm{m}^{2}$. It is the same trend of coating thickness that the minimum value was $7.84 \mu \mathrm{m}$ when WS was conducted at $500 \mathrm{~mm} / \mathrm{s}$.

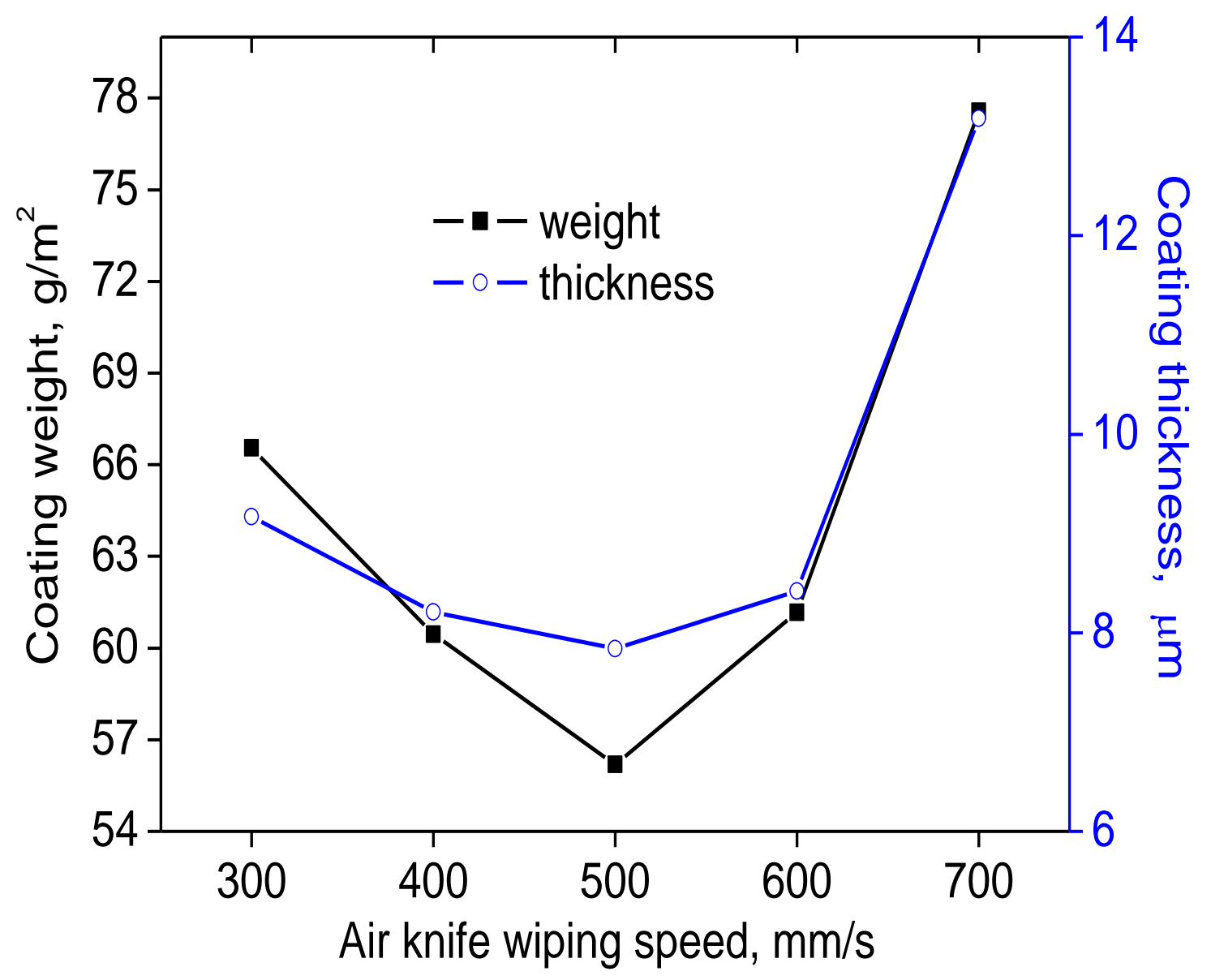

Fig.1 The Effect of WS on Coating Weight and Thickness

The element depth profiling results were analyzed by GDOES, details were shown in Fig.2. The blue and red lines displayed the concentration of zinc and iron, which crossed at the coating interface and matrix. The depth of zinc coating to the matrix thereafter could be obtained by the cross point, which was the characterization of coating thickness. The peak value of aluminum was also in the same position of the cross point, which demonstrated the exiting of inhibition layer, shown by original concentration multiple 20 with orange line. The concentration of aluminum had some difference for the five processes with WS from 300 to $700 \mathrm{~mm} / \mathrm{s}$. When WS increased from 600 to $700 \mathrm{~mm} / \mathrm{s}$, the aluminum concentration was relatively lower than the slower WS, which may be resulted by the fast moving speed of sample from the air knife, as coating could not be wiped sufficiently, so that the interface of coating and matrix will have more zinc and iron. 

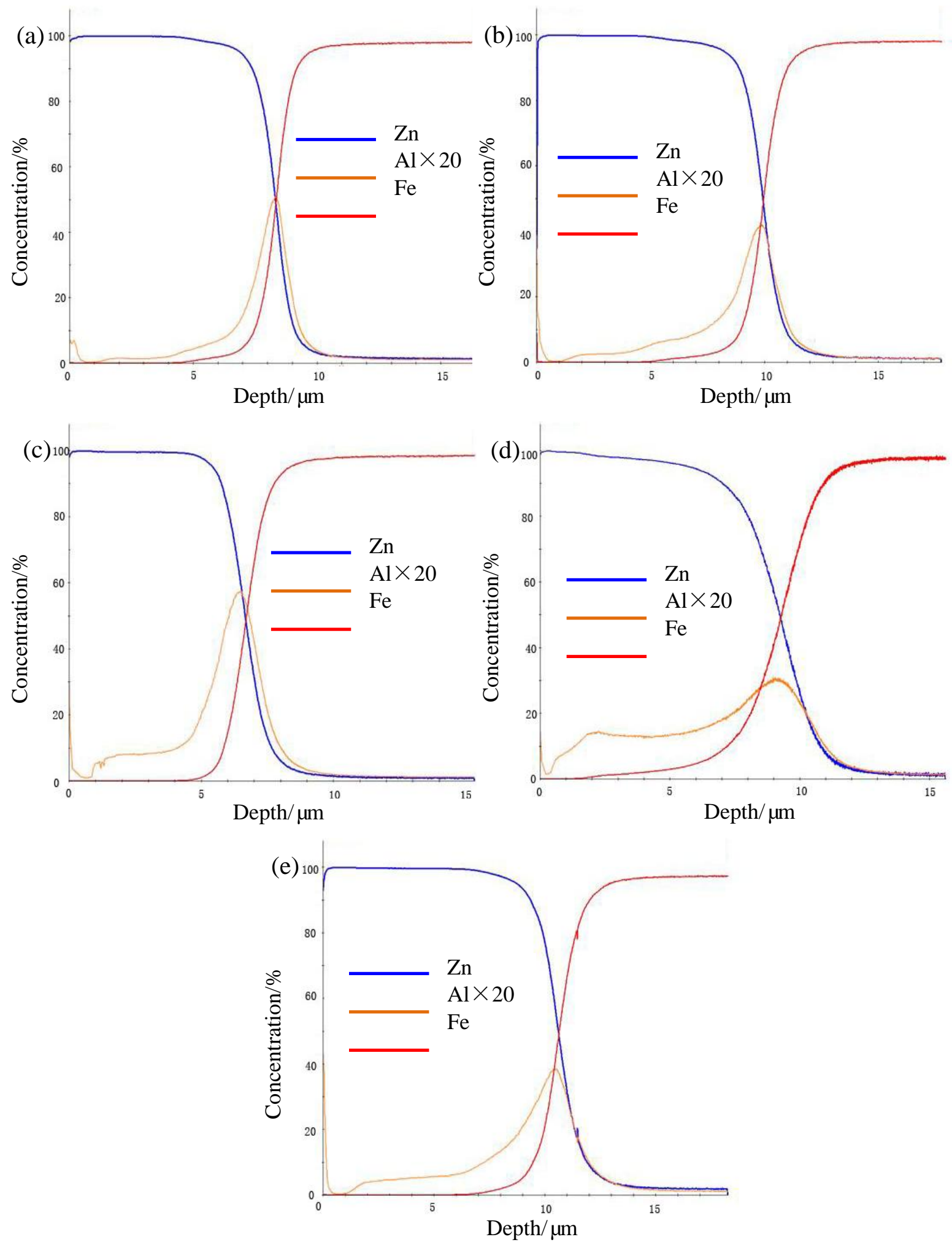

(a) FR: 500 1/min, WS: 300 mm/s; (b) FR: 500 1/min, WS: 400 mm/s; (c) FR: 500 1/min, WS: 500 mm/s; (d) FR: 500 1/min, WS: 600 mm/s (e) FR: 500 1/min, WS: 700 mm/s

Fig.2 Element Depth Profiling by GDOES

\section{Summary}

A wiping speed from 300 to $700 \mathrm{~mm} / \mathrm{s}$ was conducted by HDPS, which had an obvious effect on the coating weight and thickness. When fixing all the other dipping parameters, the weight and thickness demonstrated minimum value when WS was $500 \mathrm{~mm} / \mathrm{s}$. The result of GDOES was that, 
the peak value of aluminum was in the same position of the cross point of zinc and iron, which demonstrated the exiting of inhibition layer. With faster WS, the aluminum concentration was relatively lower than the slower WS, as coating could not be wiped sufficiently, so that the interface of coating and matrix will have more zinc and iron.

\section{References}

[1] J. Zrnik, I. Mamuzic, S. V. Dobatkin, Recent progress in high strength low carbon steels, Metabk, 2006, 45(4): 323.

[2] J. y. Guo, X. Wang, K. Q. Wang, et al, Studyon hot dip galvanizing high strength steel for automobile in ansteel, GALVATECH, 2013, 202-205.

[3] J. Staudte, J. M. Mataigne, Optimizing the Manganese And Silicon Content for Hot Dip Galvanizing of 3rd Generation Advanced High Strength Steels, GALVATECH 2013, 133.

[4] K. K. Wang, C. W. Hsu, L. Chang, et al, Role of Al in $\mathrm{Zn}$ bath on the formation of inhibition layer during hot-dip galvanizing for a $1.2 \mathrm{Si}-1.5 \mathrm{Mn}$ transformation-induced plasticity steel, Appl. Surf. Sci., 2013. 